\title{
Cost-effectiveness of the chronic disease self-management program: implications for community-based organizations
}

\author{
Rashmita Basu ${ }^{1}$ *, Marcia G. Ory ${ }^{2}$, Samuel D. Towne Jr. ${ }^{2}$, Matthew Lee Smith ${ }^{3}$, Angela K. Hochhalter ${ }^{1}$ and \\ SangNam Ahn ${ }^{4}$ \\ ${ }^{1}$ Baylor Scott \& White Health, Temple, TX, USA \\ ${ }^{2}$ Department of Health Promotion and Community Health Sciences, School of Public Health, Texas A\&M Health Science Center, College Station, TX, USA \\ ${ }^{3}$ Department of Health Promotion and Behavior, College of Public Health, The University of Georgia, Athens, GA, USA \\ ${ }^{4}$ Division of Health Systems Management and Policy, School of Public Health, The University of Memphis, Memphis, TN, USA
}

\section{Edited by:}

Sue Ellen Levkoff, University of South Carolina, USA

\section{Reviewed by:}

Sharyl Kidd Kinney, University of Oklahoma College of Public Health, USA

Sue Ellen Levkoff, University of South Carolina, USA

\section{*Correspondence:}

Rashmita Basu, Baylor Scott \& White Health, 2401 South 31st Street,

Temple, TX 76508, USA

e-mail: rbasu@sw.org
Chronic conditions are the leading cause of growing healthcare spending, disability, and death in the U.S. In the wake of national health reform, policy makers and healthcare professionals are becoming increasingly concerned in containing healthcare costs while improving quality of patient care. A basic policy question is whether the Chronic Disease Self-Management Program (CDSMP), a widely distributed evidenced-based self-managed program, can be cost-effective in managing chronic conditions while improving quality of life. Utilizing data from the National Study of CDSMP, the primary objective of the current study is to estimate cost-effectiveness of the CDSMP program among individuals with at least one chronic condition. The second objective is to determine how cost-effectiveness ratios vary by depression status. EuroQol-5D (EQ-5D) was used to measure health-related quality of life (HRQOL) of CDSMP participants, which was then converted to qualityadjusted life years (QALYs) for cost-effectiveness analysis. Participants who completed the CDSMP program experienced higher EQ-5D scores from baseline to 12-month follow-up (increased from 0.736 to $0.755 ; p<0.001$ ). The incremental cost-effectiveness ratio (ICER) ranges from $\$ 83,285$ to $\$ 31,285$ per QALYs, which can be comparable to the common benchmark of $\$ 50,000 / Q A L Y$ s. ICER by baseline depression status indicates that it will cost more per QALYs gained for those diagnosed with depression based on their Patient Health Questionnaire-8 score. However, cautions should be taken while considering this point estimate too literally because the average cost for CDSMP participants was a rough estimate and based on several simplifying assumptions. Identifying cost-effective strategies that can lower the burden of chronic disease among community-dwelling adults is critical for decision makers in allocating limited resources. Policy makers and community organizations can use this information to guide funding decisions and delivery of CDSMP programs for individuals with multiple chronic health conditions.

Keywords: chronic disease self-management, cost-effectiveness analysis, health-related quality of life, older adults, EQ-5D and quality-adjusted life years

\section{INTRODUCTION}

With the rapid aging of the baby boomer cohort, it is estimated that one in five Americans will be 65 years or older by 2030 (1). Simultaneously, the existence of multiple chronic conditions among Americans 65 years or older is becoming increasingly prevalent, with $60-75 \%$ of older adults having at least two chronic conditions (2), many of which are preventable (1). Moreover, the number of Americans with chronic conditions is projected to increase by $37 \%$ by the year 2030 (3). More than $75 \%$ of total healthcare costs are attributable to the treatment of chronic illnesses (3). Furthermore, chronic conditions among older adults are associated with lower quality of life and increased limitations in activities of daily living (4-7).

With a mission to promote health and the quality of life in Americans, the U.S. Department of Health and Human Services' Center for Disease Control and Prevention (CDC) has supported population surveillance of health-related quality of life (HRQOL) (8). HRQOL is a multi-dimensional measure, which is defined as "perceived physical and mental health over time" (9). It can be considered as a part of a person's overall quality of life that is determined by his or her health status. Because HRQOL addresses physical and mental health of a large number of individuals, it can offer current health data that public health agencies need to assess population health. In light of the growing prevalence of chronic illness, healthcare burdens, and concerns for promoting population health, service providers and policy makers are pursuing cost-effective ways to design self-management programs that can improve the health and well-being of the population $(10,11)$. As healthcare costs continue to rise for treating chronic diseases, identifying ways to manage the progression of multiple chronic conditions among older adults is critical and time-sensitive $(12,13)$. 
To promote health and the quality of life of communitydwelling older adults, federal, state, and local stakeholders are implementing evidence-based initiatives to engage individuals in managing chronic health conditions while improving health outcomes $(14,15)$. One such approach is the implementation of self-management programs that improve health and quality of life while simultaneously reducing costly healthcare utilization (16-20). These self-management programs have the potential to embrace the triple aim goals of healthcare (better care, improved patient care experience, and lower cost of care) that will enhance population health (21).

The Chronic Disease Self-Management Program (CDSMP), one of the well-studied evidence-based programs, improves health status and chronic illness symptoms while showing promise for lowering healthcare spending through the reduction in hospitalization $(22,23)$. Although evidence suggests that CDSMP can improve health outcomes among patients with chronic diseases (24-26), little is known about the cost-effectiveness of improving HRQOL among CDSMP participants. Moreover, program effectiveness may vary when chronic diseases are accompanied by depression because individuals with depression are less likely to complete the self-management education programs than those without depression (27). Thus, the current study has two goals: (1) to perform an economic evaluation of the CDSMP by utilizing a cost-effectiveness analysis of HRQOL among CDSMP participants from baseline to 6-month and 12-month follow-up; and (2) to examine how the intervention effectiveness varies for participants with or without depression at baseline.

\section{MATERIALS AND METHODS \\ NATIONAL STUDY OF CDSMP AS STUDY BASIS}

The current study utilized a change in HRQOL measures at three time points (baseline, at 6-month, and at 12-month) to examine the cost-effectiveness of the intervention among middle-aged and older adults enrolled in the National Study of the Chronic Disease Self-Management Program (CDSMP). Data were analyzed from workshops delivered nationwide by 22 licensed sites in 17 states across the nation from August 2010 to April 2011. CDSMP workshops were supported by various federal, state and local sources, healthcare organizations, and community agencies. The eligibility criteria and recruitment, intervention delivery, and referral activities are described elsewhere (22). Sites already licensed to deliver CDSMP were selected and then agreed to participate in the National Study, delivering the manualized workshops following standardized intervention protocols and submitting data for study purposes. Data were collected in person before the start of the intervention (baseline) and at 6 and 12 months post-intervention by mail/phone. Investigators had no role in leader training, workshop recruitment, or program implementation. Each CDSMP delivery site recruited people for workshops in their usual fashion, which included referrals from organizations serving older adults (e.g., senior centers, healthcare facilities, and social service organizations as well as self-referrals from other recruitment activities including flyers, brochures, and health fairs). The intervention was designed to focus on content areas including (a) techniques to manage typical responses to chronic health problems such as frustration, fatigue, pain, and isolation: (b) improving healthy behavior such as physical exercise for maintaining and improving strength, flexibility, and endurance; and (c) appropriate use of medications, effective communication with healthcare professionals $(24,28)$. For the purpose of this study, participants with complete information on indicators of HRQOL at baseline, 6-month, and 12-month follow-up were included.

\section{Study sample}

As a part of translating this intervention, CDSMP included 1,170 community-dwelling individuals at baseline, 6 months, and 12 months across the nation. A total of 825 (71\%) participants completed 12-month follow-up assessment including HRQOL measures and approximately 77\% $(n=903)$ participants completed 6-month follow-up (29). While attrition was minimal for a community-based translational research study, HRQOL information at the 6-month follow-up data was missing for 77 participants ( $N=748$ contributed to the final analyses). Few differences were observed based on data attrition. Participants who completed follow-up assessments at 6-month and 12-month tended to be older, and completers of the 6-month assessment were more likely to be non-Hispanic White (15). Institutional Review Board approval for the National Study was obtained at Stanford University and Texas A\&M University.

\section{MEASURES \\ Health-related quality of life measures}

In the current study, we focus on the healthy-days measure of HRQOL because it captures the key concepts of population health and well-being. This construct is aligned with one of CDSMP's main objectives of empowering program participants to better manage their chronic conditions and experience a higher quality of life. Healthy-days measures are important components that assess HRQOL. The HRQOL includes a set of four questions (8):

1. Would you say that in general your health is; Excellent, Very good, Good, Fair, or Poor?

2. Now thinking about your physical health, which includes physical illness and injury, for how many days during the past 30 days was your physical health not good?

3. Now thinking about your mental health, which includes stress, depression, and problems with emotions, for how many days during the past 30 days was your mental health not good?

4. During the past 30 days, for about how many days did poor physical or mental health keep you from doing your usual activities, such as self-care, work, or recreation?

In the current study, we utilize an "unhealthy days" summary measure, which is based on the second and third questions, estimates the overall number of days when physical and mental health was not good. We then calculate the number of days estimated to be healthy, which is the complement to unhealthy days measure (total number of "healthy days" limits to maximum of 30 days as this is the maximum possible value that this measure could possibly take). These items have been extensively used for evaluating program objectives in other studies $(8,30-33)$ and the validity of these measures has been confirmed in population based 
samples. Participants responded to each item with the number of days ranging from 0 to 30 .

\section{Cost measures}

The average cost per CDSMP participant varies by the number of enrolled participants per workshop with the estimated perparticipant cost ranging from $\$ 219$ to $\$ 583$ (23). In the National Study of CDSMP, 145 workshops had an average size of 12.7 $( \pm 4.18)$ participants, with the majority of workshops $(66.2 \%)$ having between 8 and 16 participants. A detailed description of the cost measures reported by CDSMP delivery sites appears elsewhere (23). Based on extant literature confirmed by experts in the delivery field, we estimated program costs at $\$ 350$ per participant, assuming an average of 10 participants in each CDSMP workshop (23). These program costs typically include licensure costs, trained peer personnel, materials, and any space rental costs (34). Because the CDSMP was a community-based program and goal that this type of self-management program is to provide evidence regarding resources needed to deliver within the community, cost data are collected at the aggregate level. In the case of CDSMP, per-participant costs were aggregated at the workshop level. Individual-level cost data are less valuable for the effective implementation of this type of community-based program.

\section{Other participant-level measures}

Participants' demographic characteristics measured at baseline included age, gender, race/ethnicity, and number of chronic conditions. Measures and a sample questionnaire can be found in English and Spanish (35). Depressive symptoms were measured using the Patient Health Questionnaire (PHQ) (36). Self-rated items (9 DSM-IV criteria) scored from 0 (not at all) to 3 (nearly everyday) were added to determine overall PHQ score of study participants at baseline. A score greater than or equal to 10 was considered clinically depressed because this cut-off point of 10 has a sensitivity and specificity of $88 \%$ in detecting a diagnosis of major depression in primary care patients (36). The reliability of the PHQ-9 is high, with a Cronbach's $\alpha$ of 0.89 and test-retest reliability of 0.84 (37). We used an eight-item version of the PHQ (38), which excludes the item that asks patients if they have been bothered by "thoughts that you would be better off dead or of hurting yourself in some way." Scores for the eight-item version of the PHQ range from 0 to 24 , and are highly correlated with scores on the nine-item version $(r=0.997)(38)$.

\section{ANALYSIS}

\section{HROOL, EQ-5D, and QALYS}

The CDC-derived measure of HRQOL is one of the most commonly used outcome measures for evaluating burden of disease in public health research. However, a single measurement such as quality-adjusted life year (QALY) is considered as a more useful measure for cost-effectiveness analyses (38-40). This is because QALY uses preference-based measures of HRQOL, which uses summary scores (i.e., utility values) to represent population preferences for different health states. Because the number of unhealthy days are not preference-based measures of HRQOL (as asked in the CDSMP survey), the CDC "healthy days" measures cannot be used directly in the cost-effectiveness analyses (41). Since the CDSMP survey did not include preference-based measure of EQ-5D, the non-preference-based scores of "healthy days" measure was converted to preference-based EuroQol 5D (EQ-5D) utilizing the method proposed by Jia and Lubetkin (42). The EQ-5D is an internationally developed preference-based $(29,43)$ method that provides a measure of utility scores to calculate QALYs which is used in cost-effectiveness analyses (44). EQ-5D estimates are obtained from healthy days by matching the cumulative distributions of the two HRQOL measures and EQ-5D from Behavioral Risk Factor Surveillance System and Medical Expenditure Panel Survey datasets (42). For example, we obtained EQ-5D utility score corresponding to number of "healthy days" measures in our sample. Detail description of the estimation method including underlying assumptions can be found in Jia and Lubetkin (42). Utility values range from 1 (best possible health state) through 0 (death) (44). We then used EQ-5D scores to calculate QALY for the calculation of cost-effectiveness ratios.

Estimation of participant specific QALYs was based on partitioning the study period into the number of follow-up assessments and weighting each time interval by the individual's utility score during that period of time (45). It is assumed that changes in utility values are linear over time, which is the most commonly used method in cost-effectiveness analysis. Individual-level QALYs are then estimated by applying the area-under the curve approach. Details of this method can be found elsewhere (42). The general expression for calculating QALYs using individual data that are fully observed (i.e., no censoring) can be written as follows (45):

$$
\text { QALY }=\sum_{t=0}^{n}\left[\frac{\left(Q_{1}+Q_{\mathrm{t}+1}\right)}{2} \times \frac{\left(T_{\mathrm{t}+1}+T_{\mathrm{t}}\right)}{T}\right]
$$

where, $n$ is the number of utility measurements over the study period (i.e., 1 year), $Q_{t}$ is the individual utility score (i.e., $E Q-5 D$ score) obtained in the $t^{\text {th }}$ measurement, $T$ is the total duration of study period expressed in terms of total number of time units in a year (e.g., months), $T_{\mathrm{t}}$ is the time period in which the $t^{\text {th }}$ measurement takes place (expressed as number of time units in a year). In our case, $n=2$ (i.e., first interval from baseline to 6-month and second interval from 6-month to 12 -month), $T=12$ (i.e., number of months in a year), and three time points as $T_{0}=0, T_{1}=6$, and $T_{2}=12$. For example, in our current study, QALYs are obtained by substituting mean EQ-5D scores and controlling for baseline utility (45):

$$
\begin{aligned}
& \text { Incremental QALY }= \\
& \qquad \sum_{t=0}^{n}\left[\frac{(0.743-0.736)}{2} \times \frac{6}{12}+\frac{(0.743-0.736)}{2}\right. \\
& \left.\times \frac{6}{12}+\frac{(0.755-0.743)}{2} \times \frac{6}{12}\right]=0.007
\end{aligned}
$$

\section{Cost-effectiveness analysis}

The strong need to control healthcare costs for the treatment of chronic diseases led us to search for interventions that produce greatest value, based on comparative economic evaluation (46). Cost-effectiveness analysis (CEA) is a type of economic evaluation method that can be utilized to assess whether money is well 
spent in a particular health promotion program (47). Funding agencies may continue to support programs on the basis of this information or may find additional interventions that can produce the best outcomes with available resources. The most widely used method for CEA is the incremental cost-effectiveness ratio (ICER), which compares differences in cost to differences in effectiveness between two competing interventions and therefore relevant for policy making decisions. In the absence of a control group, we are comparing health gains compared to no intervention (i.e., "doing nothing"). Therefore, in this case, ICER was calculated compared to baseline and measures the effectiveness of CDSMP in improving QALYs compared to "doing nothing."

An important first step of calculating ICER is to quantify its average cost of a program in order to relate the cost to specific measures of the program (48). Considering zero cost for "no intervention," the numerator of ICER is the average cost and denominator includes the mean effectiveness of the program (48, 49). In our case, the numerator is the mean program cost spent per CDSMP participant and denominator is QALYs estimates. The QALYs is particularly useful in quantifying program effectiveness and is the most commonly used measure of treatment effectiveness in CEA literature $(50,51)$. The ICER for each outcome measure was calculated by dividing per person CDSMP workshop costs by the QALYs. Therefore ICER can be indicated as:

$$
\mathrm{ICER}=\frac{\text { Average cost spent per CDSMP participant }-\$ 0}{\text { QALYs gained adjusted for baseline utility score }}
$$

\section{RESULTS}

Table 1 describes participants' characteristics at baseline. In total, 1,170 participants completed the baseline assessment. On average, participants were 65 years old, nearly $83 \%$ were female, and had an average of 13 years of education. Ethno-racial composition included 55\% non-Hispanic white, 16\% African American, 22\% Hispanic, and $6.5 \%$ others. About $79 \%$ reported two or more conditions and $79.1 \%$ of participants attended four or more workshop sessions.

Table 1 | Sample characteristics at baseline $(N=1170)$.

\begin{tabular}{lc}
\hline Variables & \% Mean (SD) \\
\hline Age (in years) & $65.4(14.3)$ \\
Female & 82.7 \\
Race/ethnicity & - \\
$\quad$ Non-Hispanic White & 55.2 \\
African American & 16.0 \\
Hispanic & 22.3 \\
$\quad$ Other & 6.5 \\
Workshop completion rate & 79.1 \\
Education (1-23) & $12.9(3.8)$ \\
At least two chronic conditions & 79.0 \\
PHO-8 depression (0-24) & $6.6(5.5)$ \\
Healthy days (0-30) & $17.9(11.5)$ \\
EQ-5D (0-1) & $0.736(0.156)$ \\
\end{tabular}

aln our sample, EQ-5D value ranges from 0.411 to 0.995 .
Table 2 represents summary statistics for healthy days and corresponding EQ-5D measures at baseline, 6-month, and 12-month during the study. Both healthy days (17.9-19.2) and corresponding EQ-5D scores (0.743-0.755) were significantly improved from baseline to 12 -month) period (with a $p$-value $<0.001$ ); however, no significant improvement was observed for these measures from baseline to 6-month.

Table 3 presents the similar statistics by baseline depression status. Changes in mean healthy days and EQ-5D scores were examined by utilizing paired $t$-test by baseline depression status. On average, participants with depression at baseline reported lower number of healthy days and their corresponding EQ-5D scores were also lower than participants who had no depression at baseline. However, both groups (depression versus no depression at baseline) showed significant improvement in healthy days and EQ-5D scores from baseline to the12-month period. These results indicate that CDSMP improves population health status among individuals with multiple chronic conditions through better disease self-management strategies.

Table 4 shows the cost-effectiveness results for the CDSMP intervention. Incremental cost-effectiveness ratios (ICER) are calculated for the overall group as well as by baseline depression status. These ratios explain how much each additional QALYs gained with CDSMP will cost. Overall, ICER ranges from $\$ 83,285$ to $\$ 31,285$ per QALYs gained for participants in the CDSMP program with the median of $\$ 50,000 /$ QALYs. ICER by baseline depression status indicates that it will cost more per QALYs gained for those diagnosed with depression based on PHQ-8 score.

\section{DISCUSSION}

Prior evidence suggests that CDSMP can significantly improve health outcomes for individuals with a variety of chronic conditions $(21,24)$. However, economic efficacy of the CDSMP on HRQOL is not well known. The current study developed a preference-based EQ-5D measure of HRQOL from healthy days to quantify the cost-effectiveness of a CDSMP program for improving QALYS gained for individuals with multiple chronic conditions. Although there is no universally acceptable threshold value for cost-effectiveness ratio (52), costs range from $\$ 50,000$ to $\$ 75000$ per QALYs gained have been considered as an acceptable value for resources expended (48).

Health-related quality of life is recognized as an important measure in public health as well as clinical research because it includes a population-based approach that addresses physical and mental health of a large number of individuals over time. Moreover, converting non-preference-based measures of HRQOL to a preference-based measure provides a way to compare the efficacy of CDSMP to other evidenced-based disease management programs in the literature. As shown in the current study, the economic value of CDSMP, as measured in dollars per QALYs gained, may have far reaching effects when magnified across the U.S. Thus, finding ways to improve the reach of the CDSMP among especially vulnerable individuals (e.g., rural, minority, low income) is a critical path of research for future studies.

Policy makers are interested in finding ways to improve the health of individuals with multiple chronic conditions as a significant share of healthcare dollars are attributed to the 
Table 2 | Changes in mean (SD) of healthy days and EQ-5D scores among CDSMP participants during the study period.

\begin{tabular}{|c|c|c|c|c|c|}
\hline \multirow[t]{2}{*}{ HRQOL measures } & \multirow[t]{2}{*}{ Baseline } & \multirow[t]{2}{*}{6 months } & \multirow[t]{2}{*}{12 months } & \multicolumn{2}{|c|}{$p$-value for the change } \\
\hline & & & & Baseline and 6 months & Baseline and 12 months \\
\hline Healthy days (0-30) & $17.9(11.5)$ & $18.5(11.4)$ & 19.2 (11.1.) & 0.25 & $<0.001$ \\
\hline EQ-5D (0-1) & $0.736(0.156)$ & $0.743(0.156)$ & $0.755(0.152)$ & 0.32 & $<0.001$ \\
\hline
\end{tabular}

Table 3 | Changes in mean (SD) of healthy days and EQ-5D scores by depression status at baseline.

\begin{tabular}{|c|c|c|c|c|c|c|c|c|c|c|}
\hline \multirow[t]{3}{*}{$\begin{array}{l}\text { HRQOL } \\
\text { measures }\end{array}$} & \multicolumn{6}{|c|}{ Depression at baseline (PHQ-8 $\geq 10$ ) } & \multicolumn{2}{|c|}{$\begin{array}{c}\text { Difference in scores: } \\
\text { baseline and 6-months }\end{array}$} & \multicolumn{2}{|c|}{$\begin{array}{c}\text { Difference in scores: } \\
\text { baseline and 12-months }\end{array}$} \\
\hline & \multicolumn{3}{|c|}{ Yes } & \multicolumn{3}{|c|}{ No } & \multirow[t]{2}{*}{ Yes } & \multirow[t]{2}{*}{ No } & \multirow[t]{2}{*}{ Yes } & \multirow[t]{2}{*}{ No } \\
\hline & Baseline & 6-months & 12-months & Baseline & 6-months & 12-months & & & & \\
\hline Healthy days & $16.4(11.5)$ & $17.3(11.4)$ & $17.9(11.2)$ & 24.1 (8.8) & $24.9(8.8)$ & $27.2(6.9)$ & 0.33 & 0.52 & 0.01 & 0.001 \\
\hline EQ-5D & $0.721(0.15)$ & $0.728(0.15)$ & $0.737(0.15)$ & $0.825(0.11)$ & $0.830(0.13)$ & $0.861(0.10)$ & 0.29 & 0.96 & 0.007 & 0.005 \\
\hline
\end{tabular}

treatment of chronic medical conditions. Deploying resources with the goal of population-based health management will facilitate efficient allocation of resources in such a way that will lower overall healthcare cost, and improve quality of care experience (50). The CDSMP provides a mechanism to deliver costeffective evidence-based strategies to those who may benefit most (e.g., being older and having co-morbid conditions). Poor quality of life and other mental health concerns has broader effects than immediate impacts on individuals with chronic conditions.

\section{LIMITATIONS}

This study builds upon an existing translational National Study of CDSMP, which was not originally designed as an economic costeffectiveness study. Hence, several variables typically included in economic analyses were not present (e.g., a comparison group or individual cost measures). While there was some participant attrition over time, the impacts appear minimal in terms of the diversity of participants in the study.

As an accommodation to available data, our study has assumed a standard per-participant costs now cited in the CDSMP literature (23). Although ICER values seem very attractive, cautions should be used to interpret too literally because these values can change substantially depending on changes in cost estimates assumption and point estimates. We acknowledge that this is a rough estimate that excludes a full consideration of all potential costs. One consideration is whether to include the opportunity cost of participating in the CDSMP program. Here, the opportunity cost would be the value of participation time in the workshop and which could be calculated based on wage forgone or the value of leisure time forgone. Since the majority of CDSMP participants are older adults, we can make the assumption that there is limited (if any) opportunity cost involved in terms of forgone wages as they are likely to be out of labor force. So, the value of leisure time could be the only way to calculate the opportunity cost of participating in the program. However, there is evidence that people do not always value the use of leisure time and it is also hard to estimate the value given the availability of survey instruments. The theoretical notion is that high motivation and retirement lower the time cost of participating in this type of health promotion program. Literature also suggests excluding time cost of participants in physical activity interventions (51).

Another limitation is that the calculation of QALYs was not adjusted for possible confounding factors which could potentially influence cots and outcome measures (45). Although the use of multiple regression method would control for this imbalance, the lack of a control group of CDSMP intervention makes this method infeasible in the current study. There are many more unmeasured benefits of the CDSMP that are not captured in the outcomes presented in the current study. For example, participants typically report many positive aspects of their participation including new social interactions. As such, the complete value of this evidencebased program is not fully measured in the current analysis and may be targeted for future study.

Using the generally accepted cost-effectiveness ratio of $\$ 50,000 /$ QALYs, results of this study indicate that CDSMP is potentially cost-effective for individuals with multiple chronic conditions. Utilizing the most widely used generic measure of HRQOL from a population-based health days measure, the current study quantifies cost-effectiveness of CDSMP. However, due to the fact that CERs evaluate how a program's costs compare to its outcomes, judgments about whether the outcomes achieved are worth than the cost are subjective and dependent on several factors (e.g., current needs and resources).

Nevertheless, we feel that this study makes a major contribution as one of the first studies to quantify the benefits of CDSMP in terms of a preference-based quality of life measure and examine the impacts for those with co-morbid depressive symptomatology. It provides a foundation for future cost-effectiveness studies of self-management programs for adults with multiple chronic conditions. 


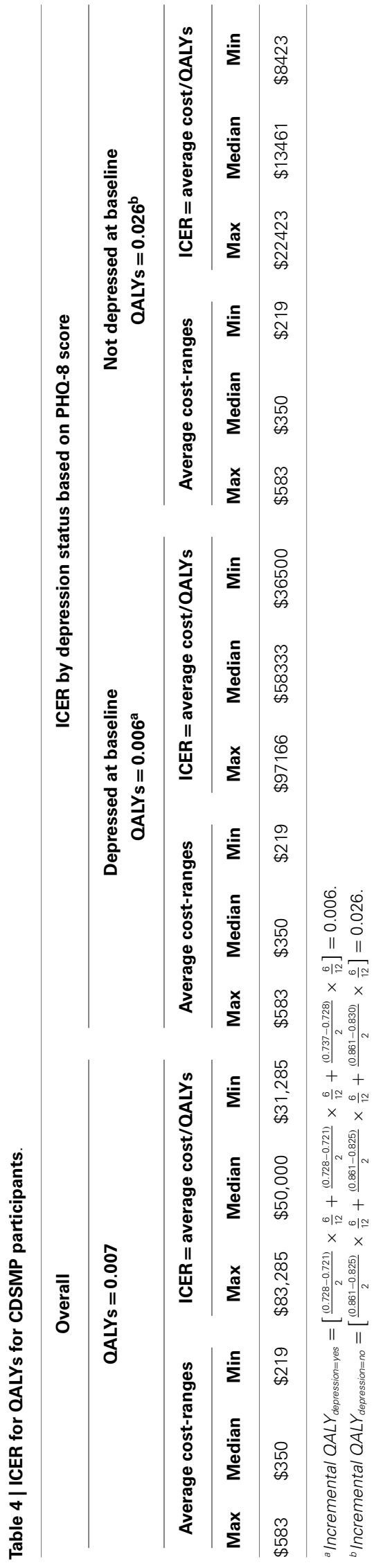

\section{ACKNOWLEDGMENTS}

The American Recovery and Reinvestment Act of 2009 (i.e., Recovery Act) Communities Putting Prevention to Work: Chronic Disease Self-Management Program initiative, led by the U.S. Administration on Aging in collaboration with the Centers for Disease Control and Prevention and the Centers for Medicare and Medicaid Services, allotted $\$ 32.5$ million to support the translation of the Stanford program in 45 States, Puerto Rico, and the District of Columbia. This research was supported by a grant to the National Council on Aging, with subcontracts to Texas A\&M University and Stanford University.

\section{REFERENCES}

1. Centers for Disease Control and Prevention. The State of Aging and Health in America 2013. Atlanta (GA): CDC. (2013). Available from: http://www.cdc.gov/ aging/pdf/state-aging-health-in-america-2013.pdf

2. Ralph NL, Mielenz TJ, Parton H, Flatley AM, Thorpe LE. Multiple chronic conditions and limitations in activities of daily living in a community-based sample of older adults in New York City, 2009. Prev Chronic Dis (2013) 10:E199. doi:10.5888/pcd10.130159

3. Anderson GF. Chronic Care: Making the Case for Ongoing Care. Princeton, NJ: Robert Wood Johnson Foundation (2010). Available from: http://www.rwjf.org/ content/dam/farm/reports/reports/2010/rwjf54583

4. Barile JP, Thompson WW, Zack MM, Krahn GL, Horner-Johnson W, Bowen SE. Multiple chronic medical conditions and health-related quality of life in older adults, 2004-2006. Prev Chronic Dis (2013) 10:E162. doi:10.5888/pcd10. 120282

5. Dominick KL, Ahern FM, Gold CH, Heller DA. Relationship of health-related quality of life to health care utilization and mortality in older adults. Aging Clin Exp Res (2002) 14:499-508. doi:10.1007/BF03327351

6. Unutzer J, Donald LP, Diehr P, Simon G, Grembowski SD, Katon W. Quality adjusted life years in older adults with depressive symptoms and chronic medical disorders. Int Psychogeriatr (2000) 12:15-33. doi:10.1017/ S1041610200006177

7. Fortin M, Lapointe L, Hudon C, Vanasse A, Ntetu AL, Maltais D. Multimorbidity and quality of life in primary care: a systematic review. Health Qual Life Outcomes (2004) 2:51. doi:10.1186/1477-7525-2-51

8. Moriaty DG, Zack MM, Kobau R. The centers for disease control and prevention's healthy days measures - population tracking of perceived physical and mental health over time. Health Qual Life Outcomes (2003) 1:37. doi:10.1186/1477-7525-1-37

9. Centers for Disease Control and Prevention. Measuring Healthy Days: Population Assessment of Health-Related Quality of Life [Internet]. Atlanta (GA): CDC (2000). Available from: http://www.cdc.gov/hrqol/pdfs/mhd.pdf

10. Harris JR, Wallace RB. The Institute of Medicine's new report on living well with chronic illness. Prev Chronic Dis (2012) 9:E148. doi:10.5888/pcd9.120126

11. Parekh AK, Barton MB. The challenge of multiple comorbidity for the US health care system. JAMA (2010) 303:1303-4. doi:10.1001/jama.2010.381

12. Parekh AK, Goodman RA, Gordon C, Koh HK. Managing multiple chronic conditions: a strategic framework for improving health outcomes and quality of life. Public Health Rep (2011) 126(4):460-71. Available from: http: //www.publichealthreports.org/cphce/126_4_460.pdf

13. Patient Protection and Affordable Care Act of 2010. Pub L. 111-148. 124 Stat. 119. (2010). Available from: http://www.gpo.gov/fdsys/pkg/PLAW-111publ148/ pdf/PLAW-111publ148.pdf

14. Barlow J, Turner A, Edwards R, Gilchrist M. A randomised controlled trial of lay-led self-management for people with multiple sclerosis. Patient Educ Couns (2009) 77:81-9. doi:10.1016/j.pec.2009.02.009

15. Ory MG, Ahn S, Jiang L, Smith ML, Ritter PL, Whitelaw N, et al. Successes of a national study of the chronic disease self-management program: meeting the triple aim of health care reform. Med Care (2013) 51:992-8. doi:10.1097/MLR.0b013e3182a95dd1

16. Brady TJ, Murphy L, O'Colmain BJ, Beauchesne D, Daniels B, Greenberg M, et al. A meta-analysis of health status, health behaviors, and health care utilization outcomes of the chronic disease self-management program. Prev Chronic Dis (2013) 10:120112. doi:10.5888/pcd10.120112 
17. Bodenheimer T, Lorig K, Holman H, Grumbach K. Patient self-management of chronic disease in primary care. JAMA (2002) 288:2469-75. doi:10.1001/jama. 288.19.2469

18. Reeves D, Kennedy A, Fullwood C, Bower P, Gardner C, Gately C, et al. Predicting who will benefit from an expert patients programme self-management course. Br J Gen Pract (2008) 58:198-203. doi:10.3399/bjgp08X277320

19. Labrecque M, Rabhi K, Laurin C, Favreau H, Moullec G, Lavoie K, et al. Can a self-management education program for patients with chronic obstructive pulmonary disease improve quality of life. Can Respir J (2011) 18: e77-81.

20. Ahmed S, Bartlett SJ, Ernst P, Paré P, Kanter GM, Perreault R, et al. Effect of a web-based chronic disease management system on asthma control and healthrelated quality of life: study protocol for a randomized controlled trial. Trials (2011) 12:260. doi:10.1186/1745-6215-12-260

21. Berwick DM, Nolan TW, Whittington W. The triple aim: care, health and cost. Health Aff (Millwood) (2008) 27(3):759-69. doi:10.1377/hlthaff.27.3.759

22. Lorig KR, Sobel DS, Stewart AL, Brown BW Jr, Bandura A, Ritter P, et al. Evidence Suggesting that a chronic disease self-management program can improve health status while reducing hospitalization: a randomized trial. Med Care (1999) 37(1):5-14. doi:10.1097/00005650-199901000-00003

23. Ahn S, Basu R, Smith ML, Jiang L, Lorig K, Whitelaw N, et al. The impact of chronic disease self-management programs: healthcare savings through a community-based intervention. BMC Public Health (2013) 13:1141. doi:10. 1186/1471-2458-13-1141

24. Ory MG, Ahn S, Jiang L, Lorig K, Ritter P, Larent DD, et al. National study of chronic disease self-management six-month outcome findings. J Aging Health (2013) 25:1258-74. doi:10.1177/0898264313502531

25. Lorig K, Holman H, Sobel D, Laurent DD. Living a Healthy Life with Chronic Conditions: Self Management of Heart Disease, Arthritis, Diabetes, Asthma, Bronchitis, Emphysema and Others. 3rd ed. Boulder, CO: Bull Publishing Company (2006).

26. Lorig K, Ritter PL, Pifer C, Werner P. Effectiveness of the chronic disease selfmanagement program for persons with a serious mental illness: a translation study. Community Ment Health J (2013) 50:96-103. doi:10.1007/s10597-0139615-5

27. Erdem E, Korda H. Self-management program participation by older adults with diabetes: chronic disease self-management program and diabetes selfmanagement program. Fam Community Health (2014) 37:134-46. doi:10.1097/ FCH.0000000000000025

28. Smith ML, Ory MG, Larsen R. Older women in a statewide evidence-based falls prevention program: who enrolls and what benefits are obtained? Womens Health Issues (2010) 20:427-34. doi:10.1016/j.whi.2010.07.003

29. Rabin R, de Charro F. EQ-5D: a measure of health status from the EuroQol Group. Ann Med (2001) 33:337-43. doi:10.3109/07853890109002087

30. Smith ML, Ory MG, Ahn S, Bazzarre TL, Resnick B. Older adults' participation in a community-based falls prevention exercise program: relationships between the EASY tool, program attendance, and health outcomes. Gerontologist (2011) 51:809-21. doi:10.1093/geront/gnr084

31. Smith ML, Ahn S, Sharkey JR, Horel S, Mier N, Ory MG. Successful falls prevention programming for older adults in Texas: rural-urban variations. J Appl Gerontol (2012) 31:3-27. doi:10.1177/0733464810378407

32. Smith ML, Ahn S, Mier N, Jiang L, Ory MG. An evidence-based program to reduce fall-related risk among older adults: a comparison of program efficacy by ethnicity. Calif J Health Promot (2012) 10:28-43.

33. NCOA. About Evidence-Based Programs. Available from: http://www.ncoa.org/ improve-health/center-for-healthy-aging/about-evidence-based-programs. html

34. Page TF, Palmer RC. Cost analysis of chronic disease self-management programs being delivered in South Florida. Health Educ J (2014) 73:228-36. doi:10.1177/0017896912471047

35. Stanford School of Medicine. Training Policies for Stanford Self-Management Programs. Palo Alto, CA: Patient Education Research Center (2014). Available from: http://patienteducation.stanford.edu/training/trnpolicies.html

36. Kroenke K, Spitzer RL. The PHQ-9; a new depression diagnostic and severity measure. Psychiatr Ann (2002) 32(9):509-15.

37. Kroenke K, Spitzer RL, Williams JB. The PHQ-9: validity of brief depression severity measure. J Gen Intern Med (2001) 16:606-13. doi:10.1046/j.1525- 1497. 2001.016009606.x
38. Kroenke K, Strine TW, Spitzer RL, Williams JB, Berry JT, Mokdad AH. The PHQ-8 as a measure of current depression in the general population. J Affect Disord (2009) 114:163-73. doi:10.1016/j.jad.2008.06.026

39. The Secretary's Advisory Committee on National Health Promotion and Disease Prevention Objectives for 2020. Phase I Report: Recommendations for the Framework and Format of Healthy People 2020 [Internet]. (2008). Available from: http://www.healthypeople.gov/sites/default/files/PhaseI_0.pdf

40. Metzler M, Kanarek N, Highsmith K, Straw R, Bialek R, Stanleyl J, et al. Community health status indicators project: the development of a national approach to community health. Prev Chronic Dis (2008) 5:A94.

41. Jia H, Lubetkin EI. Trend in quality-adjusted life-years lost contributed by smoking and obesity. Am J Prev Med (2010) 38:138-44. doi:10.1016/j.amepre.2009. 09.043

42. Jia H, Lubetkin EI. Estimating EuroQol EQ-5D scores from population healthy days data. Med Decis Making (2008) 28:491-9. doi:10.1177/0272989X07312708

43. Kind P, Dolan P, Gudex C, Williams A. Variations in population health status: results from a United Kingdom national questionnaire survey. BMJ (1998) 316:736-41. doi:10.1136/bmj.316.7133.736

44. Goldsmith KA, Dyer MT, Buxton MJ, Sharples LD. Mapping of the EQ$5 \mathrm{D}$ index from clinical outcome measures and demographic variables in patients with coronary heart disease. Health Qual Life Outcomes (2010) 8:54. doi:10.1186/1477-7525-8-54

45. Manaca A, Hawkings N, Sculpher MJ. Estimating mean QALYs in trial-based cost-effectiveness analysis: the importance of controlling for baseline utility. Health Econ (2005) 14:487-96. doi:10.1002/hec.944

46. Cellini SR, Kee JE. Cost-effectiveness and cost-benefit analysis. In: Wholey JS, Hatry HP, Newcomer KE, editors. Handbook of Practical Program Evaluation. San Francisco, CA: John Wiley \& Sons Inc (2010). 493 p.

47. Haddix A, Teutsch SM, Corso PS. Prevention Effectiveness: A Guide to Decision Analysis and Economic Evaluation. 2nd ed. Oxford: Oxford University Press (2003). 264 p.

48. Ory MG, Smith ML, Kulinski KP, Lorig K, Zenker W, Whitelaw N. Selfmanagement at the tipping point: reaching 100,000 Americans with evidencebased programs. J Am Geriatr Soc (2013) 61:821-3. doi:10.1111/jgs.12239

49. Drummond MF, Stoddart GL, Torrance GW. Methods for the Economic Evaluation of Healthcare Programmes. Oxford: Oxford University Press (1987).

50. Brownson CA, Hoerger TH, Fisher EB, Kilpatrick KE. Cost-effectiveness of diabetes self-management programs in community primary care settings. Diabetes Educ (2009) 35:761-9. doi:10.1177/0145721709340931

51. Woolf SH. A closer look at the economic argument for disease prevention. JAMA (2009) 301:536-8. doi:10.1001/jama.2009.51

52. Boheler C, Milton KE, Bull FC, Fox-Rushby JA. The cost of changing physical activity behavior: evidence from a "physical activity pathway" in a primary care setting. BMC Public Health (2011) 11:370. doi:10.1186/1471-2458$11-370$

Conflict of Interest Statement: Rashmita Basu has no conflicts of interest to disclose. Dr. Basu has no financial relationships with entities that could be perceived to influence, or that give the appearance of potentially influencing, what she wrote in the submitted work. Dr. Basu has no patents or copyrights to declare (whether pending, issued, licensed, and/or receiving royalties) relevant to the work. Dr. Basu has no other relationships or activities that readers could perceive to have influenced, or that give the appearance of potentially influencing, what she wrote in the submitted work. Marcia G. Ory has no conflicts of interest to disclose. Texas A\&M University received a grant (PI: Dr. Ory) to evaluate the National Study of CDSMP. Dr. Ory has no financial relationships with entities that could be perceived to influence, or that give the appearance of potentially influencing, what she wrote in the submitted work. Dr. Ory has no patents or copyrights to declare (whether pending, issued, licensed, and/or receiving royalties) relevant to the work. Dr. Ory has no other relationships or activities that readers could perceive to have influenced, or that give the appearance of potentially influencing, what she wrote in the submitted work. Samuel D. Towne Jr. has no conflicts of interest to disclose. Neither myself nor this institution at any time received payment or services from a third party for any aspect of the submitted work. Dr. Towne has no financial relationships with entities that could be perceived to influence, or that give the appearance of potentially influencing, what he wrote in the submitted work. Dr. Towne has no patents or copyrights to declare (whether pending, issued, licensed, and/or receiving royalties) relevant to the work. Dr. Towne has no other relationships or activities that readers 
could perceive to have influenced, or that give the appearance of potentially influencing, what he wrote in the submitted work. Matthew Lee Smith has no conflicts of interest to disclose. Neither myself nor this institution at any time received payment or services from a third party for any aspect of the submitted work. Dr. Smith has no financial relationships with entities that could be perceived to influence, or that give the appearance of potentially influencing, what he wrote in the submitted work. Dr. Smith has no patents or copyrights to declare (whether pending, issued, licensed, and/or receiving royalties) relevant to the work. Dr. Smith has no other relationships or activities that readers could perceive to have influenced, or that give the appearance of potentially influencing, what he wrote in the submitted work. SangNam Ahn has no conflicts of interest to disclose.

This paper is included in the Research Topic, "Evidence-Based Programming for Older Adults." This Research Topic received partial funding from multiple government and private organizations/agencies; however, the views, findings, and conclusions in these articles are those of the authors and do not necessarily represent the official position of these organizations/agencies. All papers published in the Research Topic received peer review from members of the Frontiers in Public Health (Public Health Education and Promotion section) panel of Review Editors. Because this Research Topic represents work closely associated with a nationwide evidence-based movement in the US, many of the authors and/or Review Editors may have worked together previously in some fashion. Review Editors were purposively selected based on their expertise with evaluation and/or evidence-based programming for older adults. Review Editors were independent of named authors on any given article published in this volume.

Received: 14 October 2014; accepted: 02 February 2015; published online: 27 April 2015.

Citation: Basu R, Ory MG, Towne SD Jr., Smith ML, Hochhalter AK and Ahn $S$ (2015) Cost-effectiveness of the chronic disease self-management program: implications for community-based organizations. Front. Public Health 3:27. doi: 10.3389/fpubh.2015.00027

This article was submitted to Public Health Education and Promotion, a section of the journal Frontiers in Public Health.

Copyright (C) 2015 Basu, Ory, Towne, Smith, Hochhalter and Ahn. This is an openaccess article distributed under the terms of the Creative Commons Attribution License (CC BY). The use, distribution or reproduction in other forums is permitted, provided the original author(s) or licensor are credited and that the original publication in this journal is cited, in accordance with accepted academic practice. No use, distribution or reproduction is permitted which does not comply with these terms. 